\title{
Comparison of bolus administration effects of lidocaine on preventing tourniquet-induced hypertension in patients undergoing general anesthesia: a randomized controlled trial
}

\author{
Ji WooK Kim', A Ran Lee ${ }^{2}$, Eun Sun Park², Min Su Yun', \\ Sung Won Ryu', Uk Gwan Kim', Dong Hee Kang ${ }^{1}$, \\ and Ju Deok Kim ${ }^{1}$
}

Received May 27, 2021

Revised August 6, 2021

Accepted August 20, 2021

\author{
Corresponding author \\ Ju Deok Kim, M.D., Ph.D. \\ Department of Anesthesiology and \\ Pain Medicine, Kosin University \\ College of Medicine, 262 Gamcheon- \\ ro, Seo-gu, Busan 49267, Korea \\ Tel: 82-51-990-6474 \\ Fax : 82-51-980-6283 \\ E-mail: uamyfriends@hanmail.net
}

${ }^{1}$ Department of Anesthesiology and Pain Medicine, Kosin University College of Medicine, Busan, ${ }^{2}$ Department of Anesthesiology and Pain Medicine, Ulsan University Hospital, Ulsan, Korea

Background: This study assessed the effect of a single bolus administration of lidocaine on the prevention of tourniquet-induced hypertension $(\mathrm{TIH})$ and compared the effect of lidocaine to that of ketamine in patients undergoing general anesthesia.

Methods: This randomized, controlled, double-blind study included 75 patients who underwent lower limb surgery using a tourniquet. The patients were administered lidocaine (1.5 $\mathrm{mg} / \mathrm{kg}, \mathrm{n}=25)$, ketamine $(0.2 \mathrm{mg} / \mathrm{kg}, \mathrm{n}=25)$ or placebo $(\mathrm{n}=25)$. The study drugs were administered intravenously $10 \mathrm{~min}$ before tourniquet inflation. Systolic blood pressure (SBP), diastolic blood pressure (DBP), and heart rate (HR) were measured before tourniquet inflation, after tourniquet inflation for $60 \mathrm{~min}$ at $10 \mathrm{~min}$ intervals, and immediately after tourniquet deflation. The incidence of $\mathrm{TIH}$, defined as an increase of $30 \%$ or more in SBP or DBP during tourniquet inflation, was also recorded.

Results: SBP, DBP, and HR increased significantly over time in the control group compared to those in the lidocaine and ketamine groups for $60 \mathrm{~min}$ after tourniquet inflation $(\mathrm{P}<$ $0.001, P<0.001$, and $\mathrm{P}=0.007$, respectively). The incidence of $\mathrm{TIH}$ was significantly lower in the lidocaine $(n=4,16 \%)$ and ketamine $(n=3,12 \%)$ group than in the control group $(n=$ 14, 56\%) $(P=0.001)$.

Conclusions: Single-bolus lidocaine effectively attenuated blood pressure increase due to tourniquet inflation, with an effect comparable to that of bolus ketamine.

Keywords: Hypertension; Ketamine; Lidocaine; Pain; Tourniquets.

\section{INTRODUCTION}

Arterial tourniquets are widely used in the operative field to prevent bleeding during surgery $[1,2]$. However, tourniquets are likely to result in the development of tourni- quet-induced hypertension (TIH), defined as an increase in systolic blood pressure (SBP) or diastolic blood pressure (DBP) of at least $30 \%$ within $1 \mathrm{~h}$ of tourniquet inflation $[3,4]$. Among patients under general anesthesia with a tourniquet, the incidence of TIH can be as high as $67 \%$ [4]. TIH can oc-

This is an Open Access article distributed under the terms of the Creative Commons Attribution Non-Commercial License (http://creativecommons.org/licenses/by-nc/4.0) which permits unrestricted non-commercial use, distribution, and reproduction in any medium, provided the original work is properly cited.

Copyright (c) the Korean Society of Anesthesiologists, 2022 
cur even at an appropriate depth of anesthesia and may be dangerous for patients with cardiovascular diseases $[1,5]$.

Although the mechanism of TIH development remains unclear, its onset is considered to be associated with the activation of $\mathrm{C}$ fibers that cause N-methyl-D-aspartate (NMDA) receptor activation associated with the central sensitization mechanism [6-8]. TIH is also associated with sympathetic nervous system activation [9]. Various methods have been used to prevent TIH during surgery [10-13]. Several studies have assessed ketamine, a pain-regulating drug, as an NMDA receptor antagonist, which effectively reduced the development of TIH when pre-administered at small doses or more $[11,14,15]$.

Lidocaine is a local anesthetic with well-known anti-inflammatory and analgesic properties [16]. The administration of a bolus dose of lidocaine with/without continuous intravenous (IV) infusion effectively prevents intraoperative pain and an increase in blood pressure and reduces the use of other anesthetics and postoperative pain $[10,17]$. A bolus administration of lidocaine $(1 \mathrm{mg} / \mathrm{kg}$ ) followed by continuous infusion $(2 \mathrm{mg} / \mathrm{kg} / \mathrm{h}$ ) reduced the incidence of TIH in patients undergoing lower limb surgery using a tourniquet [16].

However, whether a bolus administration of lidocaine without a continuous infusion can prevent TIH development in patients undergoing lower limb surgery remains unknown. Accordingly, we hypothesized that a bolus administration of lidocaine would also be effective in preventing TIH. To confirm this hypothesis, we investigated whether a bolus administration of lidocaine before tourniquet inflation could reduce the incidence of TIH in patients undergoing lower limb surgery under general anesthesia. Additionally, we compared the effect of bolus lidocaine on TIH prevention to that of bolus ketamine.

\section{MATERIALS AND METHODS}

\section{Study design}

The protocol for this randomized, double-blind, prospective study was reviewed and approved by the Institutional Review Board (no. UUHIRB-2019-01-015) and written informed consent was obtained from all study participants.

\section{Study population and intervention}

The study included 75 patients aged 18-75 years, with American Society of Anesthesiologists physical status grade
I or II who underwent lower limb surgery using a tourniquet under general anesthesia. Patients with a medical history of ischemic heart disease, peripheral vascular disease, deep vein thrombosis, or a history of allergic reactions or seizures triggered by local anesthetics were excluded from this study.

Patients were randomly assigned to one of three groups (lidocaine, ketamine, and control; allocation ratio 1:1:1) using a random number table generated by online randomization software (https://www.randomizer.org). Patients in the lidocaine and ketamine groups were intravenously administered lidocaine $1.5 \mathrm{mg} / \mathrm{kg}$ and ketamine $0.2 \mathrm{mg} / \mathrm{kg}$, respectively, which were diluted with $10 \mathrm{ml}$ of normal saline 10 min before tourniquet inflation. The control group was intravenously administered $10 \mathrm{ml}$ of normal saline. Each syringe was assigned according to the allocation. The medical staff participating in the anesthesia did not know the contents of each syringe.

\section{Anesthesia regimen and measurement}

No preoperative medications were administered to any patient. After entering the operating room, the patients were administered $5 \mathrm{ml} / \mathrm{kg}$ lactated Ringer's solution before anesthesia induction, and patient monitoring was initiated by attaching a basic monitor (electrocardiogram, pulse oximeter, noninvasive blood pressure [NIBP]). Invasive blood pressure

monitoring was applied for patients aged $\geq 65$ years, and the bispectral index (BIS; BIS VISTA ${ }^{\mathrm{TM}}$ monitor, Aspect Medical Systems, USA) was monitored to assess the adequacy of anesthetic depth during surgery. Tracheal intubation was performed with propofol $(2 \mathrm{mg} / \mathrm{kg})$, rocuronium $(0.8 \mathrm{mg} /$ $\mathrm{kg}$ ), or remifentanil ( $1 \mu \mathrm{g} / \mathrm{kg})$. The patients were ventilated in volume control mode with a tidal volume of $7 \mathrm{ml} / \mathrm{kg}$, positive end-expiratory pressure of $6 \mathrm{cmH}_{2} \mathrm{O}$, and fraction of inspired oxygen of 0.5 . The respiratory rate was controlled to maintain an end-tidal $\mathrm{CO}_{2}$ pressure of 35-40 $\mathrm{mmHg}$. After inducing anesthesia, remifentanil was continuously administered, along with $1.5-2.5 \%$ sevoflurane. The sevoflurane concentration was adjusted to maintain a BIS value between 40 and 60. After tracheal intubation, the dose of remifentanil was maintained at $0.05 \mu \mathrm{g} / \mathrm{kg} / \mathrm{min}$. When the SBP changed by more than $10 \%$ from that measured before anesthesia induction, the dose of remifentanil was increased or decreased by $0.03 \mu \mathrm{g} / \mathrm{kg} / \mathrm{min}$. If the SBP increased to > $180 \mathrm{mmHg}, 300$ $\mu \mathrm{g}$ nicardipine was administered intravenously. A tourniquet (20 cm wide) was placed on the upper thigh of the surgical side and inflated to $300 \mathrm{mmHg}$ after the lower limb was 
lifted to an angle of $45^{\circ}$ for $5 \mathrm{~min}$.

The anesthesiologists who participated in anesthesia management, the orthopedic surgeons, and the patients were all blinded to patient allocation. Another anesthesiologist, who did not participate in the patient's anesthesia, was given a group of randomly assigned patients through sealed opaque envelopes and prepared the "study drug". All syringes used in the study were the same and were labeled as "study drug". The anesthesiologist who participated in each patient's anesthesia management recorded the following values: the incidence of TIH, defined as an SBP or DBP increase $\geq 30 \%$ of the baseline value; SBP, DBP, and heart rate (HR) measured before tourniquet inflation (baseline value), after tourniquet inflation for $60 \mathrm{~min}$ at 10-min intervals, and immediately after tourniquet deflation; duration of anesthesia, surgery, tourniquet inflation; total dose of remifentanil administered during anesthesia; number of patients nicardipine administration during anesthesia; number of patients receiving fentanyl administration in the post-anesthesia care unit (PACU). The numerical rating scale (NRS, 0-10) score was measured immediately after transfer to the PACU and after $20 \mathrm{~min}$, and again $24 \mathrm{~h}$ after surgery.

The administration of all anesthetics was discontinued at the conclusion of surgery. For neuromuscular block reversal, glycopyrrolate $(0.008 \mathrm{mg} / \mathrm{kg})$ and pyridostigmine $(0.1 \mathrm{mg} /$ $\mathrm{kg}$ ) were administrated. After confirming proper neuromuscular recovery, the patients were extubated and transferred to the PACU.

\section{Sample size}

This study aimed to determine whether a single IV dose of lidocaine $(1.5 \mathrm{mg} / \mathrm{kg})$ could prevent an increase in blood pressure caused by tourniquet inflation and to compare the single IV dose of lidocaine to that of ketamine, which is already known for its preventive effects. Satsumae et al. [14] reported $\mathrm{TIH}$ incidence rates of approximately $60 \%$ and < $20 \%$ in the control and ketamine groups, respectively. Thus, we calculated the sample size in the present study assuming a $40 \%$ difference in the incidence of TIH between the control and lidocaine groups. Assuming an attrition rate of 10\%, 25 patients per group were determined to be an adequate sample size to achieve $80 \%$ power and $5 \%$ type- 1 error.

\section{Data analysis and statistical methods}

IBM SPSS Statistics for Windows, version 25.0 (IBM Corp.,
USA) was used to perform all the statistical analyses. For continuous variables, we used Kolmogorov-Smirnov tests to evaluate the distributions for normality. Normally distributed variables are expressed as means and standard deviations. Continuous variables with normal distribution were compared between the three groups using one-way Analyses of variance (ANOVA) with Tukey's post-hoc tests. Continuous variables including SBP, DBP, and HR were analyzed using repeated-measures ANOVA with Bonferroni's posttests to determine intra-group comparisons over time. For repeated measures ANOVA models, sphericity was assessed by Mauchly test and Greenhouse-Geisser correction was applied when required. Categorical variables (such as the incidence of $\mathrm{TIH}$, nicardipine administration during anesthesia, and fentanyl administration in the PACU) were analyzed by chi-square or Fisher's exact tests, as applicable. Categorical data were expressed as numbers or percentages.

Statistical significance was set at $\mathrm{P}<0.05$, except for pairwise between-group comparisons. For the problem of multiple comparisons (each group versus each other group $=3$ comparisons), a Bonferroni-corrected significance level of $0.05 / 3=0.017$ was used. We have showed Bonferroni-corrected $\mathrm{P}$ values.

\section{RESULTS}

While 82 patients were considered eligible, seven patients declined to participate in this study. Thus, a total of 75 patients were randomized, with each group including 25 patients (Fig. 1). As shown in Table 1, there were no significant differences among the three groups in the demographic profile, including sex, age, years, height, and weight. The duration of surgery, anesthesia, tourniquet inflation time, and type of surgery also did not differ significantly between the three groups.

TIH was observed in 14 of 25 patients (56\%) in the control group, occurring significantly more often compared to the lidocaine (four patients, 16\%) and ketamine (three patients, $12 \%$ ) groups $(\mathrm{P}=0.001)$ (Table 2$)$.

There was a significant interaction between the three groups over time in SBP and DBP (all P < 0.001) (Fig. 2A, B). Pairwise comparison showed a significantly higher SBP in the control group than that of the ketamine group at 50 min after tourniquet inflation $(\mathrm{P}=0.001)$. However, the difference was not statistically significant between the control and lidocaine groups $(\mathrm{P}=0.105)$ and between the ketamine and lidocaine groups $(\mathrm{P}=0.363)$. Sixty $\mathrm{min}$ after tourniquet in- 


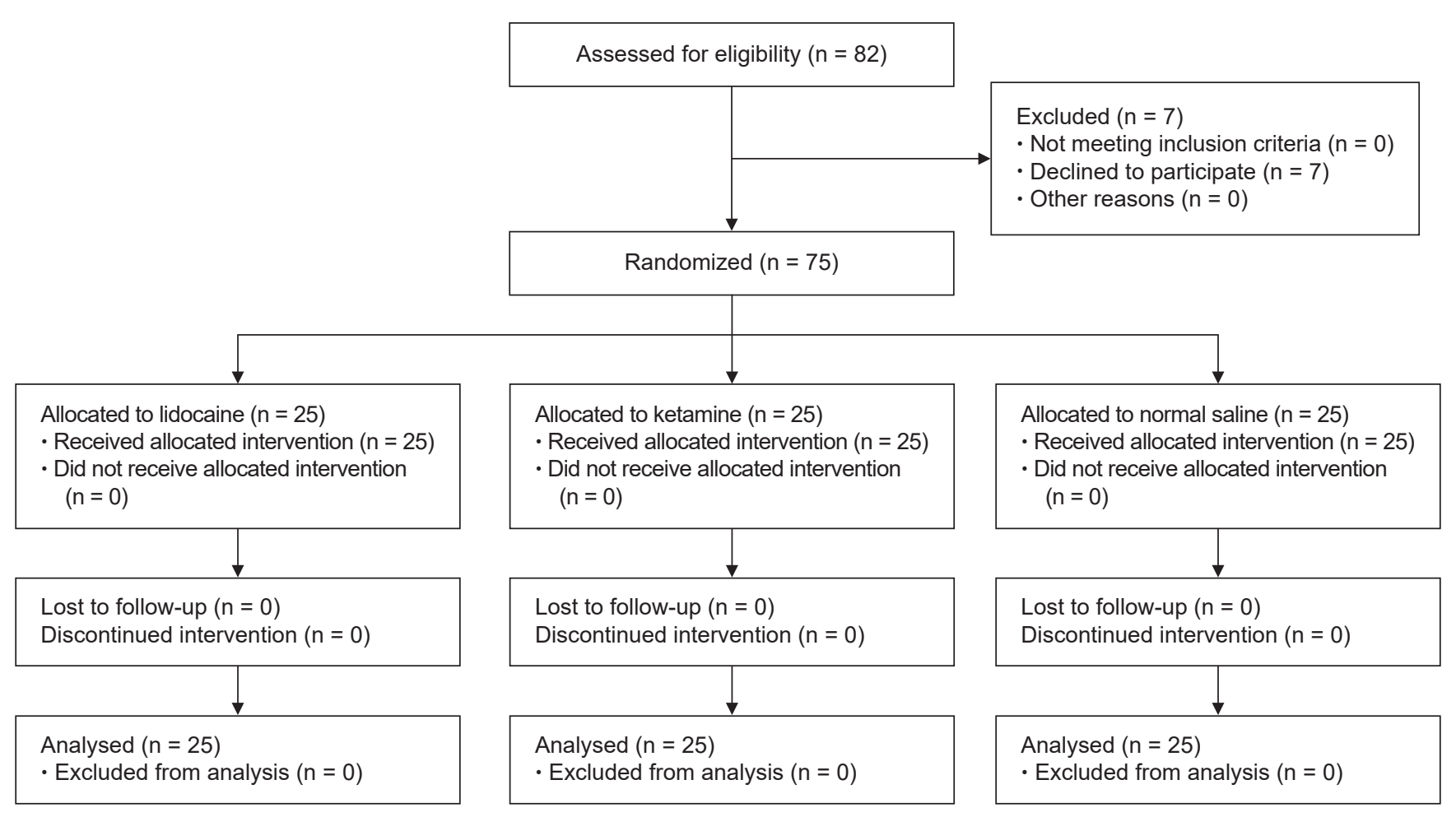

Fig. 1. Flowchart of the study participants.

Table 1. Patient and Operation Data

\begin{tabular}{|c|c|c|c|c|}
\hline Variable & Lidocaine group $(n=25)$ & Ketamine group $(\mathrm{n}=25)$ & Control group $(n=25)$ & $P$ value \\
\hline $\operatorname{Sex}(M / F)$ & $9 / 16$ & $6 / 19$ & $8 / 17$ & 0.654 \\
\hline Age (yr) & $55.2 \pm 23.2$ & $57.9 \pm 20.0$ & $56.9 \pm 22.1$ & 0.905 \\
\hline Height (cm) & $159.9 \pm 13.4$ & $158.0 \pm 11.0$ & $157.7 \pm 12.6$ & 0.789 \\
\hline Weight (kg) & $69.2 \pm 11.4$ & $65.5 \pm 11.9$ & $64.1 \pm 9.2$ & 0.245 \\
\hline Duration of surgery (min) & $83.0 \pm 10.4$ & $82.2 \pm 10.0$ & $87.4 \pm 14.5$ & 0.253 \\
\hline Duration of anesthesia (min) & $143.6 \pm 22.0$ & $142.0 \pm 2.5$ & $146.0 \pm 20.9$ & 0.809 \\
\hline Duration of tourniquet inflation (min) & $67.8 \pm 4.6$ & $66.8 \pm 4.5$ & $67.8 \pm 4.1$ & 0.653 \\
\hline Types of surgery & & & & 0.607 \\
\hline TKRA & 15 & 15 & 14 & \\
\hline Arthroscopy evaluation & 1 & 4 & 4 & \\
\hline ACL reconstruction & 5 & 2 & 5 & \\
\hline Other & 4 & 4 & 2 & \\
\hline
\end{tabular}

Values are presented as number or mean \pm SD. TKRA: total knee replacement arthroplasty, ACL: anterior cruciate ligament.

flation, the SBP of the control group was significantly higher than that of the ketamine and lidocaine groups (all $\mathrm{P}<$ 0.001). The DBP of the control group was higher than that of the ketamine and lidocaine groups at $60 \mathrm{~min}$ after tourniquet inflation ( $\mathrm{P}=0.005, \mathrm{P}=0.022$, respectively).

During tourniquet inflation, changes in HR between the three groups also showed a significant interaction with time $(P=0.007)$ (Fig. 3). Pairwise comparisons showed a higher HR in the control group compared to that in the ketamine group at $60 \mathrm{~min}$ after tourniquet inflation $(\mathrm{P}=0.022)$.

As shown in Table 2, the total doses of remifentanil used during anesthesia in the lidocaine and ketamine groups were significantly lower than that in the control group $(\mathrm{P}<$ 0.001). The numbers of patients administered nicardipine due to increased SBP to $\geq 180 \mathrm{mmHg}$ during surgery ( 5 [20\%] in the control group, $1[4 \%]$ in the lidocaine group, and 0 [none] in the ketamine group) did not differ significantly ( $\mathrm{P}$ $=0.315)$. The number of patients receiving fentanyl in the 
Table 2. Intraoperative and Postoperative Data

\begin{tabular}{|c|c|c|c|c|}
\hline Variable & Lidocaine group $(n=25)$ & Ketamine group $(n=25)$ & Control group $(\mathrm{n}=25)$ & $P$ value \\
\hline Incidence of TIH & $4(16)$ & $3(12)$ & $14(56)^{*}$ & $<0.001$ \\
\hline Total dose of remifentanil $(\mu \mathrm{g})$ & $365.2 \pm 92.4$ & $347.3 \pm 129.1$ & $622.2 \pm 109.0 *$ & $<0.001$ \\
\hline Nicardipine administration during anesthesia & $1(4)$ & $0(0)$ & $4(16)$ & 0.119 \\
\hline Fentanyl administration in the PACU & $18(72)$ & $19(76)$ & $16(64)$ & 0.734 \\
\hline NRS immediately after entering the PACU & $6.1 \pm 1.5$ & $6.2 \pm 1.3$ & $6.1 \pm 1.1$ & 0.970 \\
\hline NRS after 20 min in the PACU & $3.9 \pm 1.0$ & $3.6 \pm 0.8$ & $5.0 \pm 0.6 *$ & $<0.001$ \\
\hline NRS 24 hours after the operation & $4.0 \pm 0.8$ & $4.1 \pm 0.9$ & $5.8 \pm 1.1 *$ & $<0.001$ \\
\hline
\end{tabular}

Values are expressed as number (\%) or mean \pm SD. TIH: tourniquet-induced hypertension, NRS: numerical rating scale, PACU: postanesthesia care unit. *Compared with lidocaine and ketamine groups.
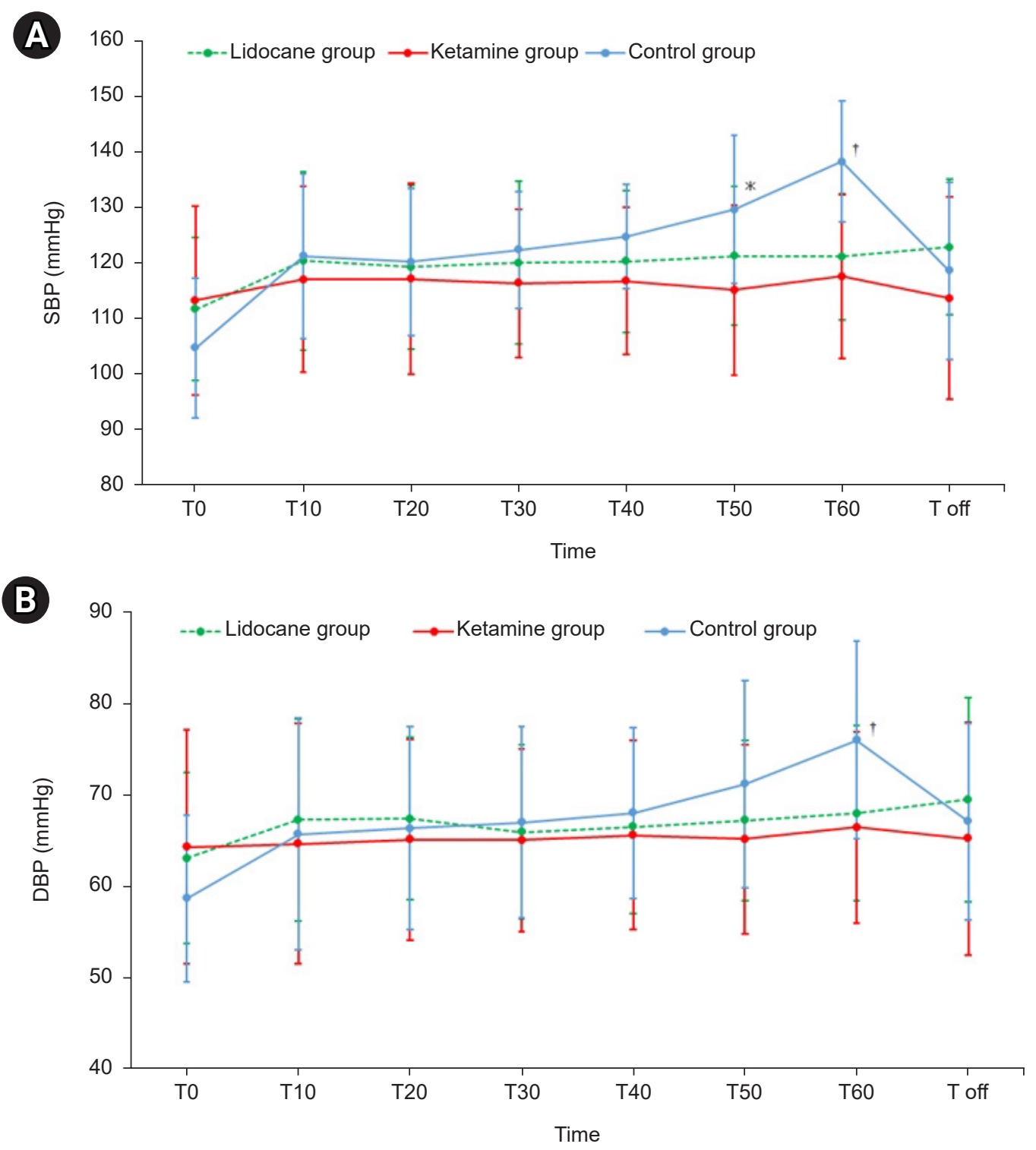

Fig. 2. Changes in blood pressure in the three groups during anesthesia. (A) Systolic blood pressure (SBP), (B) diastolic blood pressure (DBP). There was a significant interaction between the three groups over time in SBP and DBP by repeated-measures analysis of variance and Bonferroni post-hoc test (all P < 0.001). TO: immediately before tourniquet inflation, T10-T60: every 10 min after tourniquet inflation, respectively, Toff: after tourniquet deflation. ${ }^{*} \mathrm{P}<0.05$ compared to the ketamine group. ${ }^{\dagger} \mathrm{P}<0.05$ compared to the ketamine and lidocaine groups. 


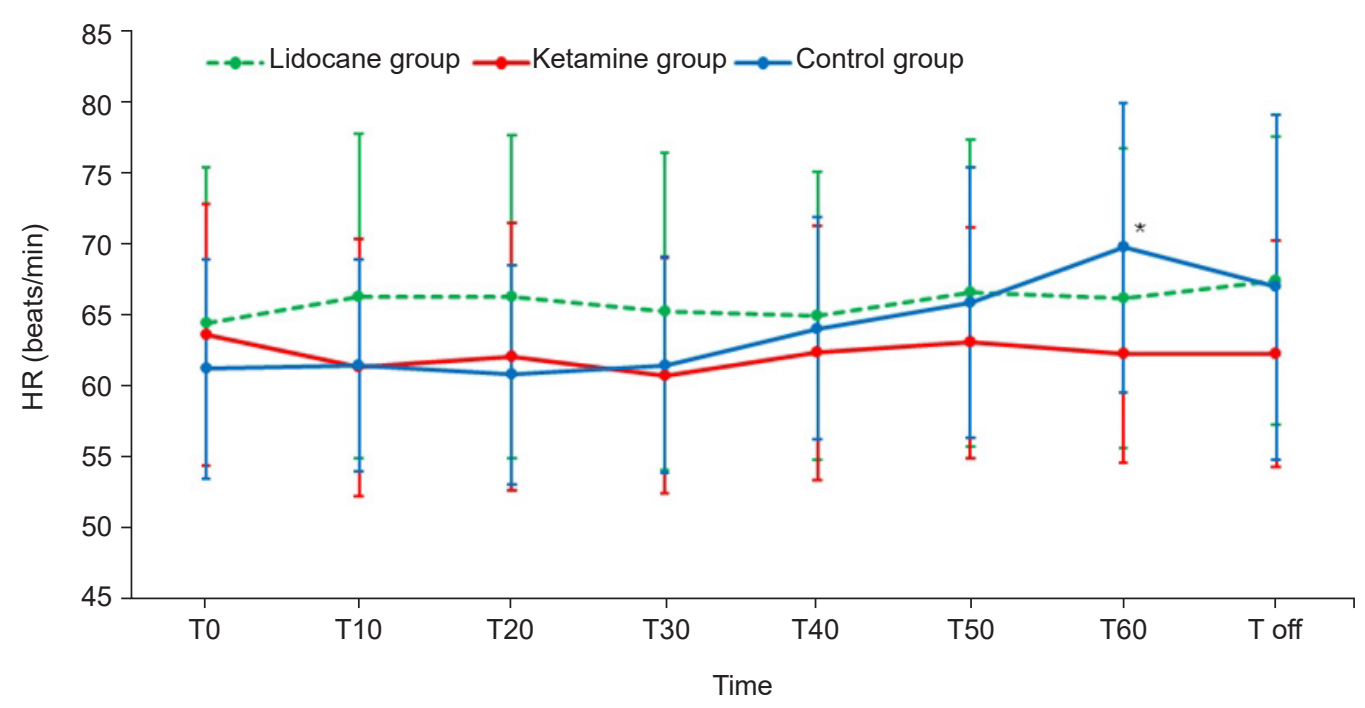

Fig. 3. Changes in heart rate (HR) in the three groups during anesthesia. There was a significant interaction in HR between the three groups over time by repeated-measures analysis of variance and Bonferroni post-hoc test $(P<0.001)$. TO: immediately before tourniquet inflation, T10-T60: every 10 min after tourniquet inflation, respectively, Toff: after tourniquet deflation. ${ }^{*} \mathrm{P}<0.05$ compared to the ketamine group.

PACU did not differ significantly among the three groups. There were also no significant differences among the three groups in NRS scores immediately after entering the PACU $(\mathrm{P}=0.970)$. However, the NRS scores measured $20 \mathrm{~min}$ after entering the PACU and $24 \mathrm{~h}$ after surgery differed significantly among the three groups (all $\mathrm{P}<0.001$ ).

\section{DISCUSSION}

The results of this study demonstrated that the bolus administration of $1.5 \mathrm{mg} / \mathrm{kg}$ lidocaine $10 \mathrm{~min}$ before tourniquet inflation prevented an increase in blood pressure caused by tourniquet inflation in patients undergoing general anesthesia, an effect similar to that for single $0.2 \mathrm{mg} / \mathrm{kg}$ dose of ketamine.

After 30-60 min of tourniquet inflation, patients may develop an increase in SBP and HR that persists until tourniquet deflation, a phenomenon known as 'tourniquet pain. An increase in blood pressure due to tourniquet application may occur despite an adequate depth of anesthesia [1]. In this study, the blood pressure and HR of patients who did not receive treatment also showed a steadily increasing pattern after tourniquet inflation, whereas the patients treated with lidocaine and ketamine before tourniquet inflation showed constant blood pressure and HR up to $60 \mathrm{~min}$ after tourniquet application. This preventive effect of lidocaine and ketamine on rising blood pressure was also effective in reducing the incidence of $\mathrm{TIH}$, which is defined as an in- crease of $30 \%$ or more in blood pressure. El-Sayed and Hasanein [10] reported that the incidence of TIH decreased from $53 \%$ to $26 \%$ with the bolus administration of $1 \mathrm{mg} / \mathrm{kg}$ lidocaine followed by a continuous infusion of $2 \mathrm{mg} / \mathrm{kg} / \mathrm{h}$ lidocaine $10 \mathrm{~min}$ before tourniquet inflation in patients undergoing anterior cruciate ligament reconstruction under general anesthesia. The present study observed a significantly reduced incidence of TIH following the administration of a 1.5 $\mathrm{mg} / \mathrm{kg}$ bolus dose of lidocaine $10 \mathrm{~min}$ before tourniquet inflation without a continuous infusion of lidocaine. Perioperative IV lidocaine may have preventive analgesic activity, likely by preventing the induction of central hyperalgesia [18]. In this study, we confirmed that the bolus administration of lidocaine prevented blood pressure increase without continuous infusion in patients in whom a tourniquet is used.

The present study compared a single bolus of lidocaine to that of ketamine, which is known for its TIH-preventing effect. Several studies have assessed the effect of preventing TIH using ketamine, an NHDA receptor antagonist. Satsumae et al. reported that preoperative IV ketamine $(0.25 \mathrm{mg} /$ $\mathrm{kg}$ or more) significantly prevented tourniquet-induced systemic arterial pressure increase in patients under general anesthesia [14]. Another study demonstrated that the preadministration of low-dose ketamine $(0.1 \mathrm{mg} / \mathrm{kg})$ attenuated tourniquet pain and arterial pressure increase using a high tourniquet pressure of $400 \mathrm{mmHg}$ and prolonged tourniquet time in healthy awake volunteers [19]. In the present study, the incidence of TIH in patients administered $0.2 \mathrm{mg} / \mathrm{kg}$ ket- 
amine was $44 \%$ lower than that in patients receiving normal saline. Moreover, we found that this dose of ketamine had a similar effect to the $1.5 \mathrm{mg} / \mathrm{kg}$ doses of lidocaine administered to patients.

Patients treated with lidocaine and ketamine had a lower NRS score $24 \mathrm{~h}$ after surgery compared to the score in patients receiving normal saline. Several studies have suggested that lidocaine and ketamine have beneficial preemptive analgesic effects in patients undergoing surgery [20,21]. Ketamine reduced postoperative morphine consumption and significantly increased the time to first analgesic request [22]. Lidocaine also has preventive effects against postoperative pain and morphine consumption after abdominal surgery [18,23]. Gholipour Baradari et al. [17] measured the visual analog scale (VAS) scores for $24 \mathrm{~h}$ after surgery following the administration of a small bolus dose of lidocaine $(1.5 \mathrm{mg} / \mathrm{kg})$ during anesthesia induction in patients undergoing cesarean section. They reported lower VAS scores among patients in the lidocaine group at the 24-hour time point compared to that in patients in the placebo group (mean VAS scores: 2.4 vs. 3.6) [17]. The results of the present study also showed lower NRS scores at $24 \mathrm{~h}$ after surgery in patients administered lidocaine or ketamine compared to the score in those administered normal saline. However, there was no difference in NRS score immediately after entering the PACU and the number of patients administered fentanyl with an NRS score of 5 or more did not differ among the three groups. However, there was a difference in NRS scores evaluated 20 min after entering the PACU. This study was unable to assess whether fentanyl used in the PACU affected these differences in NRS scores. It also did not record the total amount of analgesics used in $24 \mathrm{~h}$. Hence, further research is needed to evaluate the effect of a single bolus of lidocaine on postoperative analgesia in patients with lower extremity surgery.

In our study, anesthesia was maintained using sevoflurane, an inhalation anesthetic, and remifentanil, a synthetic opioid. Remifentanil is believed to contribute to hemodynamic stabilization by preventing the release of stress hormones when patients are exposed to stressful situations during surgery $[24,25]$. The administration of remifentanil in the maintenance of anesthesia prevents the increases in blood pressure due to tourniquet application compared to when it is not used [12,26]. In the present study, the use of lidocaine and ketamine effectively prevented the increase in blood pressure over time after tourniquet inflation, even when remifentanil was used, and also reduced the amount of remifentanil used during anesthesia. The results of this study are considered to be beneficial for patients with an increased risk of complications due to tourniquet inflation.

This study has several limitations. First, as mentioned before, the amount of analgesic, including patient-controlled analgesia (PCA), used for $24 \mathrm{~h}$ after surgery was not measured; therefore, it was not possible to assess the difference in NRS scores between the three groups $24 \mathrm{~h}$ after surgery. Second, the infusion rate of remifentanil was adjusted by increasing or decreasing according to the changes in the patient blood pressure after the induction of anesthesia. During the design process of this study, we thought that the adjustment of the infusion rate of remifentanil according to changes in patient blood pressure was commonly performed in actual clinical practice, and this was reflected in this study. However, considering the pure effect of lidocaine or ketamine on SBP, which we wanted to evaluate in this study, this could be a limitation of this study. Since this study aimed to evaluate the changes in blood pressure during surgery, it is important to measure blood pressure in the same way for all patients regardless of age. However, we measured blood pressure with NIBP if a patient's age was under 65 and conducted invasive blood pressure measurement if a patient's age was over 65 in this study. The use of different BP measurement methods depending on the patient's age may be another limitation of this study.

In conclusion, the bolus administration of lidocaine (1.5 $\mathrm{mg} / \mathrm{kg}) 10 \mathrm{~min}$ before tourniquet inflation reduced the incidence of TIH and postoperative pain, with a reduction comparable to that of bolus ketamine in patients undergoing lower limb surgery under general anesthesia.

\section{FUNDING}

None.

\section{CONFLICTS OF INTEREST}

No potential conflict of interest relevant to this article was reported.

\section{DATA AVAILABILITY STATEMENT}

The datasets generated during and/or analyzed during the current study are available from the corresponding author on reasonable request. 


\section{AUTHOR CONTRIBUTIONS}

Conceptualization: Ji WooK Kim, A Ran Lee, Ju Deok Kim. Data curation: A Ran Lee. Formal analysis: Ji WooK Kim, Ju Deok Kim. Methodology: Dong Hee Kang. Project administration: Eun Sun Park, Min Su Yun, Sung Won Ryu, Uk Gwan Kim, Dong Hee Kang. Visualization: Min Su Yun, Sung Won Ryu, Uk Gwan Kim. Writing - original draft: Ji WooK Kim, A Ran Lee. Writing -review \& editing: Ju Deok Kim. Investigation: A Ran Lee, Eun Sun Park. Resources: Sung Won Ryu, Uk Gwan Kim. Supervision: Dong Hee Kang, Ju Deok Kim.

\section{ORCID}

Ji WooK Kim, https://orcid.org/0000-0001-9944-2113

A Ran Lee, https://orcid.org/0000-0003-1045-2644

Eun Sun Park, https://orcid.org/0000-0001-8589-6413

Min Su Yun, https://orcid.org/0000-0001-8634-8136

Sung Won Ryu, https://orcid.org/0000-0001-6450-197X

Uk Gwan Kim, https://orcid.org/0000-0002-7071-7483

Dong Hee Kang, https://orcid.org/0000-0001-6614-9244

Ju Deok Kim, https://orcid.org/0000-0002-9236-5183

\section{REFERENCES}

1. Kumar K, Railton C, Tawfic Q. Tourniquet application during anesthesia: "what we need to know?". J Anaesthesiol Clin Pharmacol 2016; 32: 424-30.

2. Kam PC, Kavanagh R, Yoong FF. The arterial tourniquet: pathophysiological consequences and anaesthetic implications. Anaesthesia 2001; 56: 534-45.

3. Kaufman RD, Walts LF. Tourniquet-induced hypertension. Br J Anaesth 1982; 54: 333-6.

4. Valli H, Rosenberg PH, Kyttä J, Nurminen M. Arterial hypertension associated with the use of a tourniquet with either general or regional anaesthesia. Acta Anaesthesiol Scand 1987; 31: 27983.

5. Girardis M, Milesi S, Donato S, Raffaelli M, Spasiano A, Antonutto G, et al. The hemodynamic and metabolic effects of tourniquet application during knee surgery. Anesth Analg 2000; 91: 727-31.

6. Chabel C, Russell LC, Lee R. Tourniquet-induced limb ischemia: a neurophysiologic animal model. Anesthesiology 1990; 72: 1038-44

7. MacIver MB, Tanelian DL. Activation of C fibers by metabolic perturbations associated with tourniquet ischemia. Anesthesiology 1992; 76: 617-23.
8. Woolf CJ, Thompson SWN. The induction and maintenance of central sensitization is dependent on N-methyl-D-aspartic acid receptor activation; implications for the treatment of post-injury pain hypersensitivity states. Pain 1991; 44: 293-9.

9. Tetzlaff JE, O’Hara J Jr, Yoon HJ, Schubert A. Tourniquet-induced hypertension correlates with autonomic nervous system changes detected by power spectral heart rate analysis. J Clin Anesth 1997; 9: 138-42.

10. El-Sayed W, Hasanein R. Intraoperative lidocaine infusion attenuates tourniquet induced hypertension in patients undergoing anterior cruciate ligament reconstruction under general anesthesia. Egypt J Anaesth 2016; 32: 345-50.

11. Zaidi R, Ahmed A. Comparison of ketorolac and low-dose ketamine in preventing tourniquet-induced increase in arterial pressure. Indian J Anaesth 2015; 59: 428-32.

12. Shinoda T, Murakami W, Takamichi Y, Iizuka H, Tanaka M, Kuwasako Y. Effect of remifentanil infusion rate on stress response in orthopedic surgery using a tourniquet application. BMC Anesthesiol 2013; 13: 14

13. Li YH, Wang YQ, Zhang YJ, Zheng DY, Hu L, Tian ML. Influence of Dexmedetomidine on the tourniquet related responses in hypertension patients receiving unilateral knee arthroplasty under general anesthesia. J Arthroplasty 2015; 30: 1359-63.

14. Satsumae T, Yamaguchi H, Sakaguchi M, Yasunaga T, Yamashita S, Yamamoto S, et al. Preoperative small-dose ketamine prevented tourniquet-induced arterial pressure increase in orthopedic patients under general anesthesia. Anesth Analg 2001; 92: 1286-9.

15. Park JW, Jung YH, Baek CW, Kang H, Cha SM. Effects of low dose ketamine on tourniquet-induced haemodynamic responses during general anaesthesia. J Int Med Res 2007; 35: 600-8.

16. Hermanns H, Hollmann MW, Stevens MF, Lirk P, Brandenburger T, Piegeler T, et al. Molecular mechanisms of action of systemic lidocaine in acute and chronic pain: a narrative review. Br J Anaesth 2019; 123: 335-49.

17. Gholipour Baradari A, Firouzian A, Hasanzadeh Kiabi F, Emami Zeydi A, Khademloo M, Nazari Z, et al. Bolus administration of intravenous lidocaine reduces pain after an elective caesarean section: findings from a randomised, double-blind, placebo-controlled trial. J Obstet Gynaecol 2017; 37: 566-70.

18. Koppert W, Weigand M, Neumann F, Sittl R, Schuettler J, Schmelz M, et al. Perioperative intravenous lidocaine has preventive effects on postoperative pain and morphine consumption after major abdominal surgery. Anesth Analg 2004; 98: 1050-5.

19. Takada M, Fukusaki M, Terao Y, Kanaide M, Yamashita K, Mat- 
sumoto S, et al. Preadministration of low-dose ketamine reduces tourniquet pain in healthy volunteers. J Anesth 2005; 19: $180-2$.

20. Yardeni IZ, Beilin B, Mayburd E, Levinson Y, Bessler H. The effect of perioperative intravenous lidocaine on postoperative pain and immune function. Anesth Analg 2009; 109: 1464-9.

21. Fiorelli A, Mazzella A, Passavanti B, Sansone P, Chiodini P, Iannotti $\mathrm{M}$, et al. Is pre-emptive administration of ketamine a significant adjunction to intravenous morphine analgesia for controlling postoperative pain? A randomized, double-blind, placebo-controlled clinical trial. Interact Cardiovasc Thorac Surg 2015; 21: 284-90.

22. Yang L, Zhang J, Zhang Z, Zhang C, Zhao D, Li J. Preemptive analgesia effects of ketamine in patients undergoing surgery. A meta-analysis. Acta Cir Bras 2014; 29: 819-25.
23. Murthy Tk K, Kumar Pv V. Effect of perioperative intravenous lignocaine infusion on haemodynamic responses and postoperative analgesia in laparoscopic cholecystectomy surgeries. Anesth Pain Med 2018; 8: e63490.

24. Weale NK, Rogers CA, Cooper R, Nolan J, Wolf AR. Effect of remifentanil infusion rate on stress response to the pre-bypass phase of paediatric cardiac surgery. Br J Anaesth 2004; 92: 18794.

25. Scott LJ, Perry CM. Remifentanil: a review of its use during the induction and maintenance of general anaesthesia. Drugs 2005; 65: 1793-823.

26. Jung JY, Han JH, Yi JW, Kang JM. Remifentanil prevents tourniquet-induced arterial pressure increase in elderly orthopedic patients under sevoflurane/N2O general anesthesia. Int J Med Sci 2012; 9: 311-5. 